\title{
Sistem Penunjang Keputusan Menggunakan Metode Topsis Untuk Menentukan Kelayakan Bantuan Rumah Tidak Layak Huni (Rtlh) Pada Desa Sumbaga
}

\author{
Hiya Nalatissifa ${ }^{1}$, Yudi Ramdhani ${ }^{2}$ \\ ${ }^{1,2}$ Adhirajasa ReswaraSanjaya University \\ E-Mail: ${ }^{1}$ hiyanalatissifa@gmail.com, ${ }^{2}$ yudiramdhani.yrm@gmail.com
}

\begin{abstract}
ABSTRAK
Memiliki rumah yang layak untuk dihuni merupakan keinginan setiap manusia, kemiskinan merupakan factor utama seseorang tidak dapat memenuhi kebutuhan primer maupun sekundernya. Upaya pemerintah untuk meningkatkan kesejahteraan rakyat adalah dengan menga dakan berbagai program penanggulangan kemiskinan, salah satunya pemberian dana RTLH yang harus tepat diberikan kepada penduduk yang tidak mampu. Akan tetapi dalam pelaksanaannya petugas mengalami kesulitan dalam pengolahan data, sehingga diperlukan suatu Sistem Penunjang Keputusan (SPK) yang dapat membantu untuk menentukan penerima bantuan RTLH. Salah satumetode SPK yaitu metode TOPSIS yang merupakan metode yang dapat membantu proses pengambilan keputusan secara optimal/praktis dengan konsep yang sederhana/mudah dipahami. Desa Sumbaga merupakan salah satu desa yang membutuhkan sebuah SPK dalam menentukan masyarakat yang berhak menerima bantuan dana RTLH. Pihak desa mengalami kesulitan dalam hal penetapan penerima bantuan karena banyaknya data calon penerima dan kriteriakriteria yang harus dipertimbangkan dalam pengolahan datanya, membuat keputusan dilakukan secara subyektif atau mengandalkan perkiraan/prediksi, sehingga masih terdapat penyaluran bantuan yang tidak tepat sasaran. Hasil penelitian ini yaitu system pendukung keputusan kelayakan bantuan rumah tidak layak huni (RTLH) dengan menggunakan metode TOPSIS yang dibangun sebagai alat bantu dalam menentukan kelayakan bantuan RTLH.
\end{abstract}

\section{Kata kunci: Metode TOPSIS, RumahTidakLayakHuni (RTLH),SistemPenunjang Keputusan (SPK)}

\begin{abstract}
Having a decent house to live in is the desire of every human being, poverty is a major factor a person cannot fulfill his primary or secondary needs. The government's effort to improve the people's welfare is by conducting various poverty reduction programs, one of which is the provision of RTLH funds which must be appropriately given to disadvantaged populations. However, in its implementation the officer has difficulty in processing data, so we need a Decision Support System (SPK) that can help to determine the recipient of RTLH assistance. One of the SPK methods is the TOPSIS method which is a method that can help the decision making process optimally / practically with a simple / easy to understand concept. Sumbaga Village is one of the villages that needs a SPK in determining the community entitled to receive RTLH funding. The village experienced difficulties in determining the recipient of aid due to the large amount of prospective recipient data and the criteria that must be considered in processing the data, making decisions done subjectively or relying on estimates / predictions, so that there is still distribution of aid that is not on target. The results of this study are the decision support system for the eligibility of uninhabitable housing (RTLH) using the TOPSIS method which was built as a tool in determining the feasibility of RTLH assistance
\end{abstract}

Keywords: TOPSIS Method, Uninhabitable Home (RTLH), Decision Support System (SPK)

Author Korespondensi (Hiya Nalatissifa)

Email : hiyanalatissifa@gmail.com

\section{PENDAHULUAN}

Setiap manusia berkeinginan memiliki rumah yang layak untuk ditinggali agar merasakan aman dan nyaman saat menempatinya. Namun kemiskinan merupakan factor utama seseorang tidak dapat memenuhi kebutuhan primer maupun sekundernya [1]. Rumah merupakan kebutuhan manusia yang harus diperhatikan karena menyangkut kesejahteraan masyarakat. Kebutuhan akan rumah layak huni semaki nmeningkat sesuai dengan peningkatan jumlah penduduk Indonesia, 
namun tidak seiring dengan meningkatnya tara fhidup masyarakat ekonomi lemah yang mengharuskan hidup dalam RTLH [2].Tercatat pada tahun 2017 penduduk miskin di Provinsi Jawa Tengah berjumlah 3,90 Juta Orang [3].

Upaya pemerintah untuk meningkatkan kesejahteraan rakyat Indonesia saat ini telah dilakukan dengan mengadakan berbagai program penanggulangan kemiskinan, salah satunya berupa pemberian dana RTLH [4].Bantuan dana RTLH adalah program pemerintah berupa bantuan dana untuk memperbaiki rumah yang tidak layakhuni. Bantuan dana RTLH harus tepat diberikan kepada penduduk kurang mampu yang memenuhi criteria sebagai syarat penerima bantuan. Akan tetapi dalam pelaksanaannya petugas mengalami kesulitan dalam pengolahan datanya, sehingga diperlukan suatusi sistem penunjang keputusan yang dapat membantu dalam menentukan penerima kelayakan bantuan RTHL[5][12].

Sistem Pendukung Keputusan (SPK) merupakan sistem yang dapat membantu permasalahan dalam menentukan keputusan yang akurat dan tepatsasaran[6][14][15]. SPK atau Decision Support System (DSS) merupakan sistem yang dapat mendukung pengambilan keputusan manajerial untuk masalah semi terstruktur. Keputusan yang diberikan dapatmeningkatkan efektifitas pengambilank eputusan dan pengambilan keputusan dapat lebihobjektif[7][13].

Metode yang digunakan dalam SPK salah satunya adalah metode TOPSIS. Metode TOPSIS yaitu metode yang dapat membantu pengambilan keputusan yang optimal dalam menyelesaikan masalah keputusan secara praktis[7][12].Halini karena konsep yang sederhana dan mudah dipahami, komputasi yang efisien, dan dapat mengukur kinerja relative dari alternatif-alternatif keputusan dalam bentuk matematis sederhana[8].Prinsipnya adalah alternative yang dipilih memiliki jarak terpendek dari solusi ideal positif dan jarak terjauh dari solusi ideal negatif[9].

Desa Sumbaga adalah desa yang berada di Kabupaten Tegal yang membutuhkan Sebuah SPK, dikarenakan DesaSumbaga merupakan salah satu desa yang mendapat perhatian pemerintah dalam merealisasikan program bantuan dana RTLH. Untuk menentukan masyarakat yang berhak menerima batuan dana
RTLH, pihak desa mengalami kesulitan dalam hal penetapan penerima bantuan karena banyaknya data calon penerima dan kriteriakriteria yang harus dipertimbangkan dalam pengolahan datanya, keputusan diambil dengan cara subyektif atau mengandalkan perkiraan/prediksi, sehingga masih terdapat penyaluran bantuan yang tidak tepat sasaran. Hal tersebut dikhawatirkan dapat menimbulkan kesenjangan sosial antara masyarakat.

Maka untuk mempermudah Desa Sumbaga dalam proses seleksi kelayakan bantuan RTLH, penulis mengadakan penelitian dan pembangunan aplikasi system penunjang keputusan yang berjudul "Sistem Penunjang Keputusan Menggunakan Metode TOPSIS untuk Menentukan Kelayakan Bantuan Rumah TidakLayak Huni (RTLH) pada Desa Sumbaga".

\section{METODELOGI}

Metode penelitian adalah sekumpulan peraturan, kegiatan, dan prosedur yang digunakan oleh pelaku suatu disiplin ilmu[10]. Berikut metode penelitian yang digunakan penulis:

\subsection{Metode Pengembangan Perangkat Lunak}

Model waterfall(air terjun) adalah "Model sekuensial linier atau alur hidup klasik. Model air terjun memberikan pendekatan alur hidup perangkat lunak secara terurut yang dimulai dari analisis sampai tahap pendukung (support) [11].

Berikut adalah gambar model air terjun menurut Sukamto dan Shalahuddin:

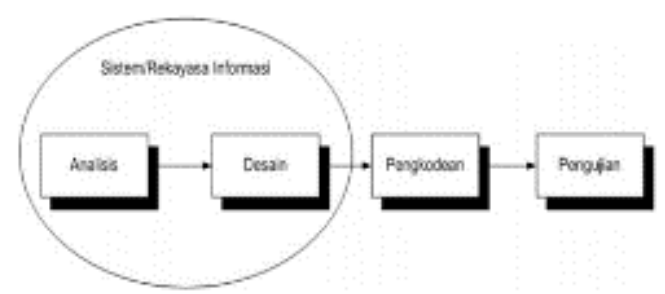

Gambar 1. Ilustrasi Model Waterfall

a. Analisis Kebutuhan Perangkat Lunak

Proses pengumpulan kebutuhan dilakukan secara intensif untuk menspesifikasikan kebutuhan perangkat lunak agar dapat dipahami oleh user. Dalam tahap ini penulis menentukan kebutuhan fungsional dan non fungsional dalam membuat aplikasi

b. Desain

Desain perangkat lunak adalah proses multi langkah yang focus pada desain pembuatan 
program termasuk arsitektur perangkat lunak, struktur data, representasi antar muka, dan prosedur pengkodean. Pada tahap ini penulis membuat perancangan aplikasi seperti perancangan basis data dan kebutuhan tabel yang digambarkan dalam bentuk ERD (Entity Relationship Diagram) dan LRS (Logical Record Structure) serta UML (Unified Modelling Language) yang meliputi Usecase Diagram dan Activity Diagram dengan Database.

c. Pembuatan Kode Program

Desain ditranslasikan kedalam program perangkat lunak. Hasil dari tahap ini yaitu program computer disesuaikan dengan desain yang telah dibuat kedalam bahasa pemrograman seperti HTML, PHP dan CSS dengan bantuan software pengolahan bahasa pemrograman Sublime Text dengan Apache sebagai web server dan MySQL sebagai database.

d. Pengujian

Pengujian fokus pada perangkat lunak dari segifungsional dan logic. Hal ini dilakukan agar meminimalisir kesalahan (error) dan memastikan keluaran yang dihasilkan sesuai dengan yang diinginkan. pengujian yang digunakan yaitu white box testing yang merupakan pengujian yang didasarkan pada pengecekan terhadap detail perancangan dan black box testing yang merupakan pengujian secara fungsional seperti pengujian untuk validasi.

e. Pendukung (Support)

Tahap pendukung dapat mengulang proses pengembangan mulai dari analisis spesifikasi untuk merubah perangkat lunak yang sudah ada, tetapi tidak untuk membuat perangkat lunak yang baru. Dalam tahap ini penulis mempersiapkan infrastruktur software pendukung seperti pemasangan web server XAMPP, pemasangan aplikasi SPK, serta memberitahukan cara pengoperasian aplikasi SPK.

\subsection{Metode Pengambilan Keputusan}

Sistem Pendukung Keputusan (SPK) merupakan sistem yang dapat membantu permasalahan dalam menentukan keputusan yang akurat dan tepat sasaran[6]. SPK atau Decision Support System (DSS) merupakan sistem yang dapat mendukung pengambilan keputusan manajerial untuk masalah semi terstruktur. Keputusan yang diberikan dapat meningkatkan efektifitas pengambilan keputusan dan pengambilan keputusan dapat lebih objektif[7].

Penulis menggunakan metode TOPSIS sebagai metode pengambilan keputusan. Metode TOPSIS merupakan sebuah metode yang mampu membantu proses pengambilan keputusan yang optimal untuk menyelesaikan masalah keputusan secara praktis[7]. Hal ini karena konsep yang mudah dipahami dan sederhana, komputasi yang efisien, dan mampu mengukur kinerja relative dari alternatifalternatif keputusan dalam bentuk matematis sederhana[8]. Dengan prinsip bahwa alternatif yang dipilih memiliki jarak terpendek dari solusi ideal positif dan jarak terjauh dari solusi ideal negatif[9].

Tahapan dalam metode topsis adalah sebagai berikut[12]:

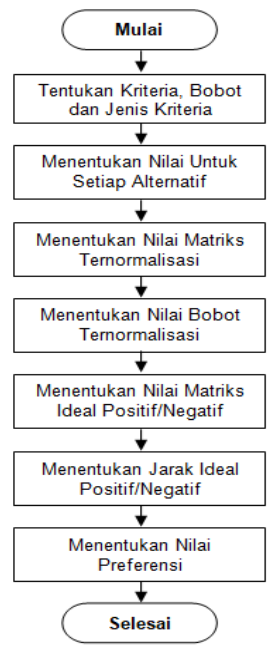

Gambar 2. TahapanMetodeTopsis

\section{HASIL DAN PEMBAHASAN}

Berdasarkan metode penelitian yang telah dilakukan, makahasil yang didapatkan adalah system penunjang keputusan menggunakan metode Topsis untuk menentukan kelayakan bantuan rumah tidak layak huni (RTLH) pada Desa Sumbaga.

\subsection{Perhitungan Metode Topsis}

Berikut langkah-langkah perhitungan system penunjang keputusan menggunakan metode topsis dalam menentukan kelayakan bantuan RTLH pada desa sumbaga.

a. MenentukanJenis-JenisKriteriadalam proses seleksi penerimaan bantuan RTLH. 
Dalam penelitian ini, kriteria-kriteria yang dibutuhkan dalam proses seleksi penerimaan bantuan RTLH pada Desa Sumbaga adalah dinding, atap, lantai, pekerjaan, penghasilan, jumlah tanggungan, ukuran rumah dan fasilitas MCK.

b. Menentukan Rangking SetiapAlternatif Pada Setiap Kriteria, Nilai 1 Sampai 5.

Keterangan:

$1=$ SangatBuruk

$2=$ Buruk

$3=$ Cukup

$4=$ Baik

$5=$ SangatBaik

Tabel 1. Kriteria dan BobotKriteria

\begin{tabular}{|c|c|c|c|}
\hline No & Kriteria & Data Awal & $\begin{array}{l}\text { Rang- } \\
\text { king }\end{array}$ \\
\hline \multirow{4}{*}{1.} & \multirow{4}{*}{ Dinding } & Tembok & 2 \\
\hline & & Papan & 3 \\
\hline & & Triplek & 4 \\
\hline & & Bambu & 5 \\
\hline \multirow{3}{*}{2.} & \multirow{3}{*}{ Atap } & Asbes & 3 \\
\hline & & Seng & 4 \\
\hline & & Genteng & 5 \\
\hline \multirow{5}{*}{3.} & \multirow{5}{*}{ Lantai } & Granit & 1 \\
\hline & & Keramik & 2 \\
\hline & & Semen & 3 \\
\hline & & Papan & 4 \\
\hline & & Tanah & 5 \\
\hline \multirow{4}{*}{4.} & \multirow{4}{*}{ Pekerjaan } & PNS/Guru & 1 \\
\hline & & Pedagang & 2 \\
\hline & & Petani & 3 \\
\hline & & Buruh & 4 \\
\hline \multirow{5}{*}{5.} & \multirow{5}{*}{ Penghasilan } & $>5 \mathrm{Jt}$ & 1 \\
\hline & & $4 \mathrm{Jt}-3 \mathrm{Jt}$ & 2 \\
\hline & & $2 \mathrm{Jt}-3 \mathrm{Jt}$ & 3 \\
\hline & & $\begin{array}{l}500 \mathrm{rb}-1 \\
\mathrm{Jt}\end{array}$ & 4 \\
\hline & & $<500 \mathrm{rb}$ & 5 \\
\hline \multirow{4}{*}{6.} & \multirow{4}{*}{$\begin{array}{l}\text { JumlahTangg } \\
\text { ungan }\end{array}$} & $1-2$ Org & 1 \\
\hline & & $3-5$ Org & 2 \\
\hline & & $6-8$ Org & 3 \\
\hline & & $>8$ Org & 4 \\
\hline \multirow{5}{*}{7.} & \multirow{5}{*}{$\begin{array}{l}\text { UkuranRuma } \\
\mathrm{h}\end{array}$} & $>35 \mathrm{~m}^{2}$ & 1 \\
\hline & & $26-35 \mathrm{~m}^{2}$ & 2 \\
\hline & & $16-25 \mathrm{~m}^{2}$ & 3 \\
\hline & & $10-15 \mathrm{~m}^{2}$ & 4 \\
\hline & & $<10 \mathrm{~m}^{2}$ & 5 \\
\hline
\end{tabular}

\begin{tabular}{|l|l|l|l|}
\hline 8. & $\begin{array}{l}\text { Fasilitas } \\
\text { MCK }\end{array}$ & - & 4 \\
\hline
\end{tabular}

c. Menentukan Nilai Untuk Setiap Matriks (Matriks Keputusan)

Menentukan nilai dari masing-masing alternative terhadap kriteria sehingga

Terbentuk matriks Xij (Matriks Keputusan).

Tabel 2. Matrik Keputusan $\left(X_{\mathrm{ij}}\right)$

\begin{tabular}{|l|c|c|c|c|c|c|c|c|}
\hline $\begin{array}{l}\text { Alternatif/ } \\
\text { Kriteria }\end{array}$ & Dinding & Atap & Lantai & PKJ & PHSLN & JT & UR & FM \\
\hline Andi & 4 & 5 & 3 & 3 & 4 & 4 & 3 & 3 \\
\hline Sumirah & 3 & 4 & 4 & 3 & 3 & 3 & 4 & 2 \\
\hline Daryo & 3 & 4 & 3 & 2 & 4 & 2 & 2 & 3 \\
\hline Serah & 5 & 5 & 4 & 3 & 3 & 3 & 3 & 4 \\
\hline Ropii & 4 & 3 & 2 & 2 & 3 & 1 & 3 & 3 \\
\hline
\end{tabular}

d. Menentukan Matriks Ternormalisasi

Setelah matriks keputusan, kemudian membuat matriks keputusan ternormalisasi yang berfungsi untuk memperkecil range data. Berikut penyelesaian matrik ternormalisasi:

Elemen $\mathrm{R}_{\mathrm{ij}}$ hasil dari normalisasi decision matrix $\mathrm{R}$ dengan metode Euclidean length of a vector adalah :

Dengani $=1,2,3, \ldots \mathrm{m} ;$ dan $\mathrm{j}=1,2,3 \ldots \mathrm{n}$

$$
R_{i j}=\frac{X_{i j}}{\sqrt{\sum_{i=1}^{m} X_{i j}^{2}}}
$$

Contoh:

Matriks $\mathrm{x}(1,1)=4$

$$
\begin{gathered}
=\sqrt{4^{2}+3^{2}+3^{2}+5^{2}+4^{2}} \\
=\sqrt{16+9+9+25+16} \\
=\sqrt{75} \\
=8,660 \quad
\end{gathered}
$$

Matriks $\mathrm{x}(1,2)=5$

$$
\begin{aligned}
& =\sqrt{5^{2}+4^{2}+4^{2}+5^{2}+3} \\
& =\sqrt{25+16+16+25+9} \\
& =\sqrt{91} \\
& =9,539
\end{aligned}
$$

Matriks $\mathrm{x}(1,3)=3$

$$
\begin{aligned}
& =\sqrt{3^{2}+4^{2}+3^{2}+4^{2}+2^{2}} \\
& =\sqrt{9+16+9+16+4} \\
& =\sqrt{54}
\end{aligned}
$$




$$
=7,348
$$

Sehingga hasil pembaginya adalah:

\begin{tabular}{|l|l|l|l|l|l|l|l|l|}
\hline Pembagi & 8,660 & 9,539 & 7,348 & 5,916 & 7,681 & 6,244 & 6,855 & 6,855 \\
\hline
\end{tabular}

Tabel 3. Nilai MatriksTernormalisasi (rij)

\begin{tabular}{|l|c|c|c|c|c|c|c|c|}
\hline $\begin{array}{l}\text { Alternatif/ } \\
\text { Kriteria }\end{array}$ & Dinding & Atap & Lantai & PKJ & PHSLN & JT & UR & FM \\
\hline Andi & 0,462 & 0,524 & 0,408 & 0,507 & 0,521 & 0,641 & 0,438 & 0,438 \\
\hline Sumirah & 0,346 & 0,419 & 0,544 & 0,507 & 0,391 & 0,480 & 0,584 & 0,292 \\
\hline Daryo & 0,346 & 0,419 & 0,408 & 0,338 & 0,521 & 0,320 & 0,292 & 0,438 \\
\hline Serah & 0,577 & 0,524 & 0,544 & 0,507 & 0,391 & 0,480 & 0,438 & 0,584 \\
\hline Ropii & 0,462 & 0,314 & 0,272 & 0,391 & 0,391 & 0,160 & 0,438 & 0,438 \\
\hline
\end{tabular}

e. Menentukan Nilai Bobot Ternormalisasi.

Setelah membuat matriks ternormalisasi, kemudian membuat nilai bobot ternormalisasi.

Jadi,

Bobot kriteria Dinding $\quad=4$

Bobot kriteria Atap $\quad=4$

Bobot Kriteria Lantai $\quad=3$

Bobot kriteria Pekerjaan $=3$

Bobot kriteria Penghasilan $=3$

Bobot kriteria Jumlah Tanggungan $=3$

Bobot kriteria Ukuran Rumah $\quad=3$

Bobot kriteria Fasilitas MCK $=3$

Nilai bobot ternormalisasi dapat dihitung dengan:

$$
V_{i j}=r_{i j} x W_{i}
$$

$i=1,2, \ldots, m$ dan $j=1,2, \ldots, n$.

Dimana $W_{j}$ adalah bobot dari kriteria atau atribut ke $j^{\text {th }}$

Contoh x (1,1): 4

$$
\begin{aligned}
V_{i j} & =0,462 \times 4 \\
& =1,848
\end{aligned}
$$

Contoh x (1,2): 5

$$
\begin{aligned}
V_{i j} & =0,524 \times 4 \\
& =2,096
\end{aligned}
$$

Contoh x (1,3): 3

$$
\begin{aligned}
V_{i j} & =0,408 \times 3 \\
& =1,224
\end{aligned}
$$

Tabel 4. Nilai BobotTernormalisasi $\left(V_{i j}\right)$

\begin{tabular}{|l|c|c|c|c|c|c|c|c|}
\hline $\begin{array}{l}\text { Alternatifl } \\
\text { Kriteria }\end{array}$ & Dinding & Atap & Lantai & PKJ & PHSLN & JT & UR & FM \\
\hline Andi & 1,848 & 2,096 & 1,224 & 1,521 & 1,563 & 1,923 & 1,314 & 1,314 \\
\hline Sumirah & 1,348 & 1,676 & 1,632 & 1,521 & 1,172 & 1,440 & 1,752 & 0,876 \\
\hline Daryo & 1,348 & 1,676 & 1,224 & 1,014 & 1,563 & 0,960 & 0,876 & 1,314 \\
\hline Serah & 2,308 & 2,096 & 1,632 & 1,521 & 1,173 & 1,440 & 1,314 & 1,752 \\
\hline Ropii & 1,848 & 1,256 & 0,816 & 1,014 & 1,173 & 0,480 & 1,314 & 1,314 \\
\hline
\end{tabular}

f. Menentukan Nilai Matriks Ideal Positif/Negatif.

$\mathrm{A}^{+}$merupakan solusi ideal positif yang diharapkan, sedangkan $\mathrm{A}^{-}$merupakan solusi ideal negatif. Makin kecilnilai $\mathrm{A}^{+}$dan makin besar nilai A`nya,maka makin besar kemungkinan sebuah alternative untuk terpilih.

$\mathrm{A}^{+}=\left\{\left(\max \mathrm{v}_{i j} \mid j \in c_{b}\right),\left(\min _{i j} \mid j \in c_{c}\right)\right\}=\left\{v_{j}^{+} j=1,2, \ldots, m\right\}$ $\mathrm{A}^{-}=\left\{\left(\min \mathrm{v}_{i j} \mid j \in c_{b}\right),\left(\max \mathrm{v}_{i j} \mid j \in c_{c}\right)\right\}=\left\{v_{j}^{-} j=1,2, \ldots, m\right\}$

Tabel 5. Nilai Matriks Ideal Positif/Negatif $\left(\mathrm{A}^{+}\right.$ dan $\mathrm{A}^{-}$)

\begin{tabular}{|l|c|c|c|c|c|c|c|c|}
\hline $\begin{array}{l}\text { Alternatiff } \\
\text { Kriteria }\end{array}$ & Dinding & Atap & Lantai & PKJ & PHSLN & JT & UR & FM \\
\hline $\mathrm{A}^{+}$ & 2,308 & 2,096 & 1,632 & 1,521 & 1,563 & 1,923 & 1,752 & 1,752 \\
\hline $\mathrm{A}^{-}$ & 1,348 & 1,256 & 0,816 & 1,014 & 1,173 & 0,480 & 0,876 & 0,876 \\
\hline
\end{tabular}

g. Menentukan Jarak solusi Ideal Positif/Negatif

Rumus untuk memperoleh nilai jarak solusi ideal Positif $\mathrm{S}^{+}$dan nilai jarak solusi ideal Negatif $S^{-}$adalah sebagai berikut :

$$
\begin{aligned}
& S_{I}^{+}=\sqrt{\sum_{j=1}^{m}\left(v_{j}^{+}-v_{i j}\right)^{2}, j-1,2, \ldots m} \\
& S_{I}^{-}=\sqrt{\sum_{j=1}^{m}\left(v_{i j}-v_{j}^{-}\right)^{2}, j-1,2, \ldots m}
\end{aligned}
$$

Perhitungan:

$$
\begin{aligned}
\mathrm{S}_{\mathrm{andi}^{+}} & =\sqrt{\frac{(2,308-1,848)^{2}+(2,096-2,096)^{2}+(1,632-1,224)^{2}+(1,521-1,521)^{2}+}{(1,563-1,563)^{2}+(1,923-1,923)^{2}+(1,752-1,314)^{2}+(1,752-1,314)^{2}}} \\
& =\sqrt{0,212+0+0,166+0+0+0+0,192+0,192} \\
& =\sqrt{0,762} \\
& =0,873 \\
\mathrm{~S}_{\text {andi }}{ }^{-} & =\sqrt{(1,848-1,384)^{2}+(2,096-1,256)^{2}+(1,224-0,816)^{2}+(1,521-1,014)^{2}+} \\
& =\sqrt{0,215+0,706+0,166+0,257+0,152+0,082+0,192+0,192} \\
& =\sqrt{3,962} \\
& =1,990
\end{aligned}
$$


Sehingga diperoleh nilai jarak solusi ideal Positif $\mathrm{S}^{+}$dan nilai jarak solusi ideal Negatif $\mathrm{S}^{-}$ adalah sebagai berikut:

Tabel 6. Jaraksolusi Ideal Positif/Negatif

\begin{tabular}{|l|c|c|}
\hline Alternatif & $\mathbf{S}^{+}$ & $\mathbf{S}^{-}$ \\
\hline Andi & 0,873 & 1,990 \\
\hline Sumirah & 1,477 & 1,669 \\
\hline Daryo & 1,827 & 0,956 \\
\hline Serah & 0,759 & 2,088 \\
\hline Ropii & 2,102 & 0,773 \\
\hline
\end{tabular}

h. Menentukan Nilai Preferensi (Kedekatan Relatif)

Setelah menghitung nilai jaraksolusi ideal Positif $\mathrm{S}^{+}$dan nilai jarak solusi ideal Negatif $\mathrm{S}^{-}$, selanjutnya adalah menghitung nilai preferensi (Kedekatan Relatif).

$R C_{i}=\frac{S_{I}^{-}}{S_{I}^{+}+S_{I}^{-}}, i=1,2, \ldots$ mdan $0 \leq R C_{i} \leq 1$

Contoh Perhitungan:

$$
\begin{aligned}
& \mathrm{RC}_{\text {and }}=\frac{1,990}{0,873+1,990}=\frac{1,990}{2,863}=0,695 \\
& \mathrm{RC}_{\text {Sumirah }}=\frac{1,669}{1,477+1,669}=\frac{1,669}{3,146}=0,530 \\
& \mathrm{RC}_{\text {Daryo }}=\frac{0,956}{1,827+1,956}=\frac{0,956}{2,783}=0,344 \\
& \mathrm{RC}_{\text {Serah }}=\frac{2,088}{0,759+2,088}=\frac{2,088}{2,847}=0,733 \\
& \mathrm{RC}_{\text {Ropii }}=\frac{0,773}{2,102+0,773}=\frac{0,733}{2,875}=0,268
\end{aligned}
$$

Sehingga diperoleh Nilai Preferensi (Kedekatan Relatif) adalah sebagai berikut:

Tabel 7. Nilai Preferensi (Kedekatan Relatif)

\begin{tabular}{|l|c|c|}
\hline Alternatif & RC & Rangking \\
\hline Andi & 0,695 & 2 \\
\hline Sumirah & 0,530 & 3 \\
\hline Daryo & 0,344 & 4 \\
\hline Serah & 0,733 & 1 \\
\hline Ropii & 0,268 & 5 \\
\hline
\end{tabular}

\subsection{Analisa Sistem Berjalan}

Proses bisnis system seleksi penerimaan bantuan RTLH pada Desa Sumbaga adalah sebagai berikut:

a. RT/RW Menyerahkan daftar data calon penerima bantuan RTLH kepada petugas kelurahan, yaitu Kepala Seksi Kesejahteraan Rakyat (Kasi Kesra).

b. Petugas kelurahan (Kasi Kesra) menerima data dan mengecek data calon penerima RTLH apakah sudah benar atau tidak.

c. Jika sudah sesuai, petugas kelurahan melakukan survei dan melakukan penilaian kondisi rumah calon penerima ban tuan RTLH.

d. Petugas kelurahan (Kasi Kesra) menyerahkan hasil survei kepada kepala desa untuk disetujui.

Berikutuse case diagram dan activity diagram proses seleksi penerimaan bantuan RTLH pada Desa Sumbaga:

1. Use case diagram yang sedang berjalan

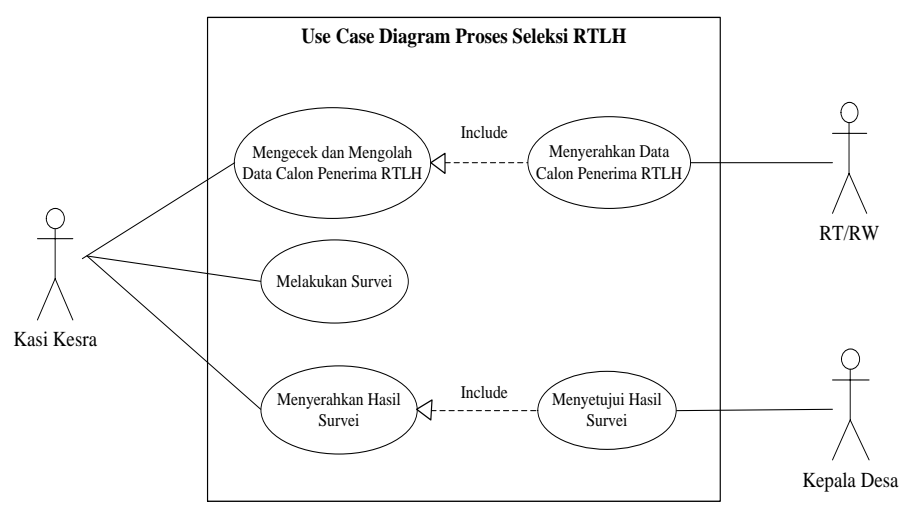

Gambar 3. Use Case Diagram Proses Seleksi RTLH Yang Sedang Berjalan

2. Activity diagram yang sedang berjalan

a. Activity diagram proses mengecek data calon penerima bantuan RTLH pada Desa Sumbaga dimulai dari RT/RW 
menyerahkan data ke Kasi Kesra, kemudian Kasi Kesramengecek data, apakah Data pemohon sudah sesuai atau tidak.

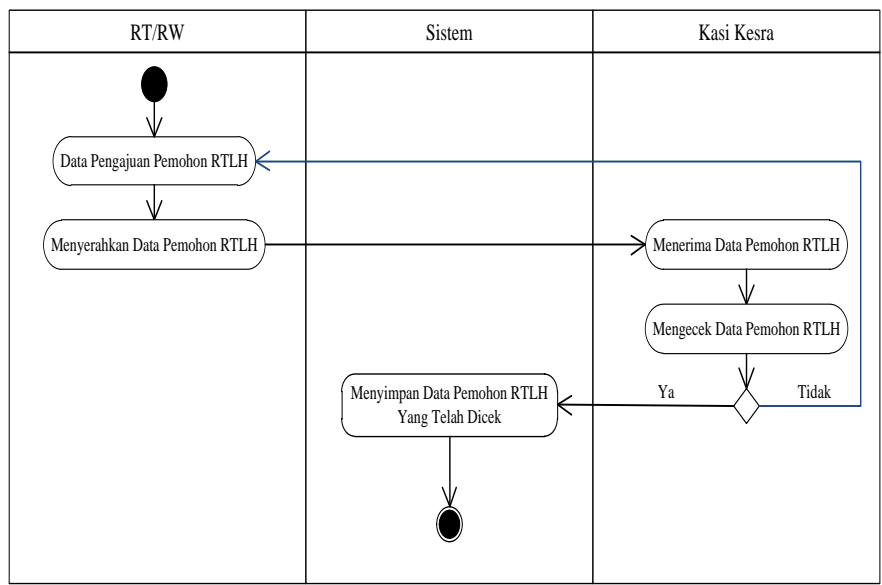

Gambar 4. Activity Mengecek Data Pemohon

b. Activity diagram proses melakukan survei dan menyerahkan hasil survei penerima bantuan RTLH pada Desa Sumbaga.

Kegiatan melakukan survey, yaitu dengan cara melihat kondisi rumah warga, kemudian melakukan wawancara dengan pemohon/calon penerima bantuan RTLH berdasarkan syarat kriteria yang telah ditentukan untuk mendapatkan hasil survei, kemudian hasil survey diserahkan kekepala desa untuk disetujui.

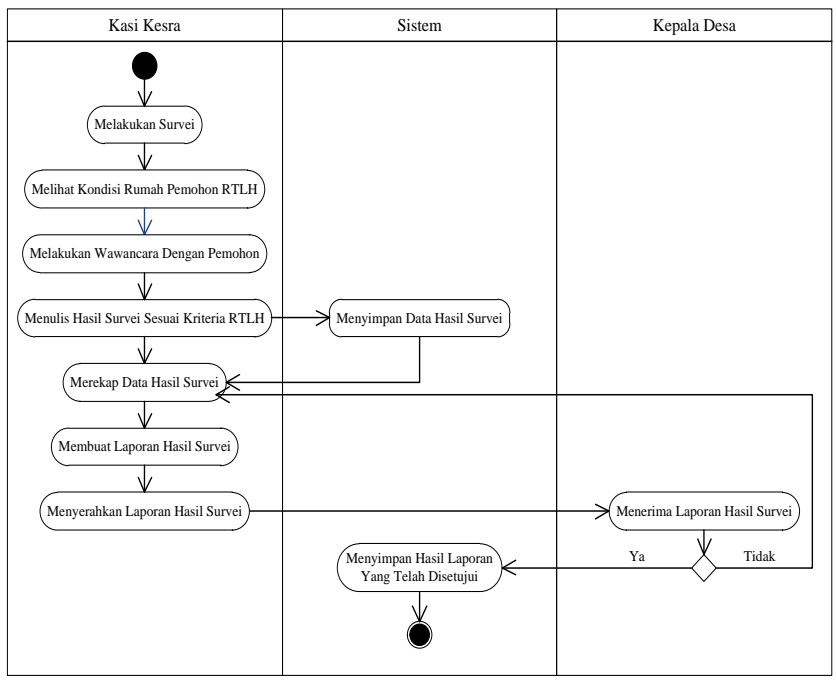

Gambar 5. Activity Melakukan Survei dan Menyerahkan Hasil Survei

\subsection{SistemUsulan}

\section{A. Use Case Diagram}

Berikut use case diagram system usulan prose seleksi penerima bantuan Rumah Tidak Layak Huni (RTLH).

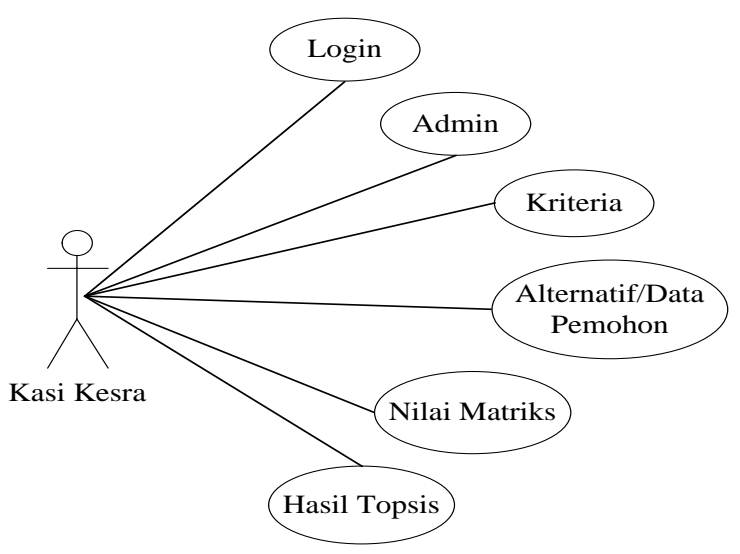

Gambar 6. Use Case DiagramAplikasi SPK RTLH

Penjelasan dari use case Gambar 6. adalah Kasi Kesra dapat melakukan login, mengelola data admin, mengelola data kriteria dan mengelola data alternatif/data pemohon, serta dapat mengisi/menambah nilai matrik dan dapat melihat hasil perhitungan metode TOPSIS.

\section{B. Activity Diagram}

Berikutactivity diagram sistemusulanprose seleksi penerima RTLH:

1. Activity Diagram Login

Untuk login kesistem, admin meng input username dan password.

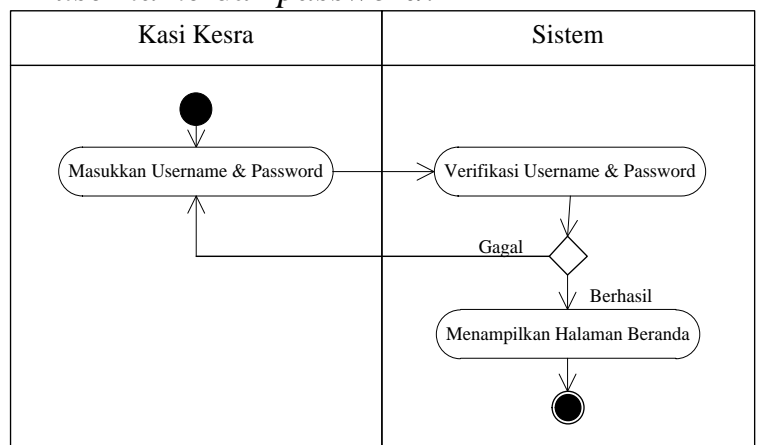

Gambar 7. Activity Diagram MelakukanLogin

2. Activity Diagram Mengelola Data Admin. Pada sistem, admin dapat melakukan penambahan data admin, mengubah data admin dan menghapus data admin. 


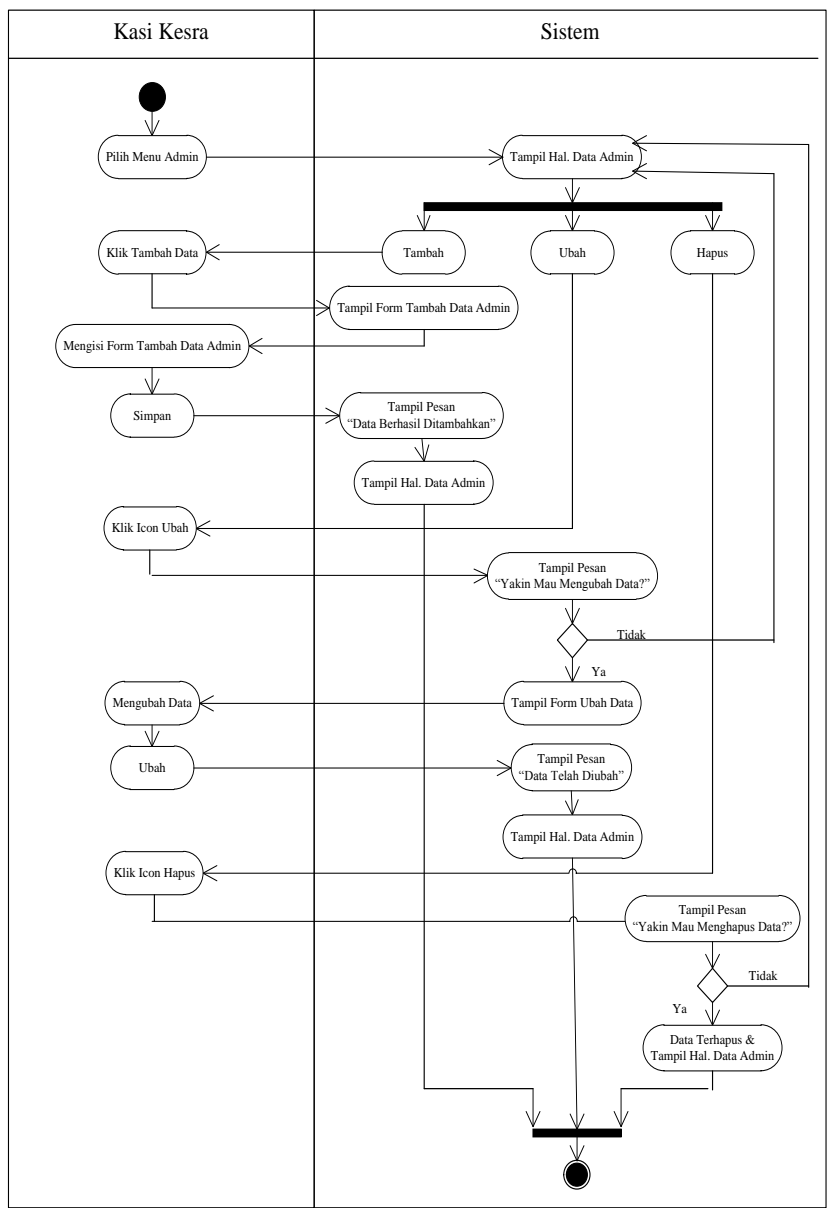

Gambar 8. Activity Diagram Mengelola Data Admin

3. Activity Diagram Mengelola Nilai Matriks Berikut adalah activity diagram mengelola nilai matriks yang dilakukan admin kesistem. Pada sistem, admin dapat memasukkan nilai alternatif pada tiapkriteria.

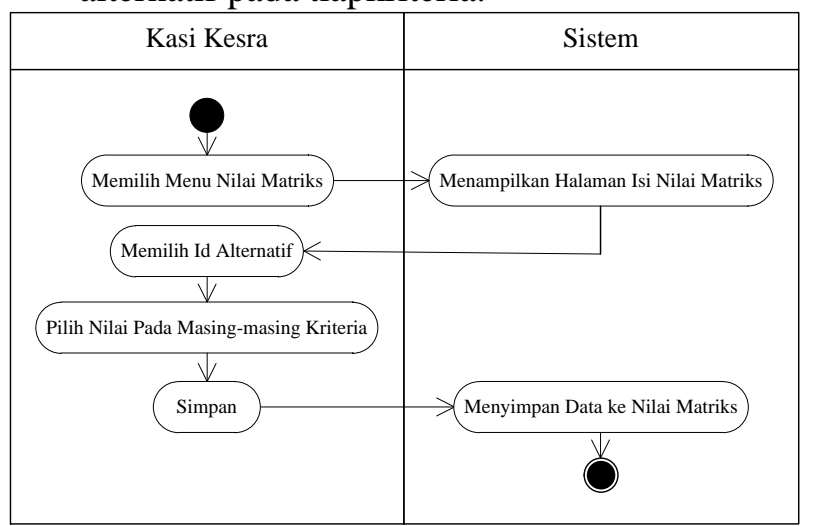

Gambar 9. Activity Diagram Mengelola Nilai Matrik

a. Activity Diagram Melihat Hasil Topsis

Pada sistem, admin dapat melihat hasil dari nilai matriks, hasil dari nilai matriks ternormalisasi, hasil dari nilai bobot ternormalisasi, hasil dari matriks ideal positif/negatif, hasil dari jarak solusi ideal positif/negatif, dan dapat melihat hasil dari nilai preferensi/hasil akhir dari perhitungan metode TOPSIS.

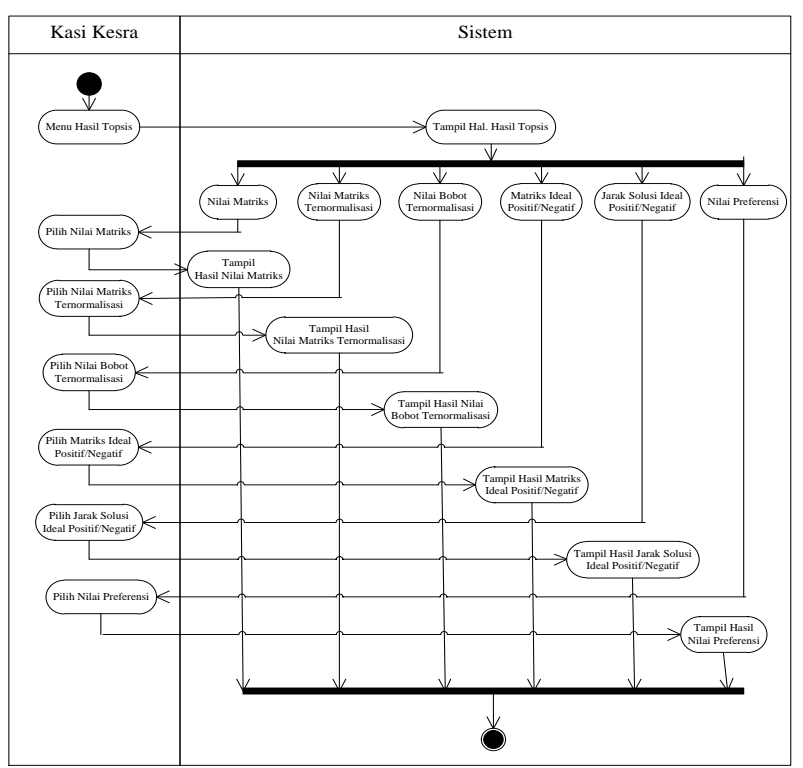

Gambar 10. Activity Diagram Melihat Hasil Topsis

\section{Design Database}

Database pada system penunjang keputusan menggunakan metode TOPSIS untuk menentukan kelayakan Bantuan RTLH pada Desa Sumbaga bertujuan untuk memelihara dan menyimpan data yang telahdiolah agar dapat diakses dengan cepat dan mudah. Berikut adalah database system usulan pada system penunjang keputusan menggunakan metode TOPSIS untuk menentukan kelayakan bantuan RTLH pada Desa Sumbaga.

1. Entity Relationship Diagram (ERD)

Berikut adalah ERD Pada sistemusulan. Terdapat 3 entitas, yaitu entitas alternatif, entitas nilai_matrik, dan entitas kriteria dengan masing-masing atributnya. 


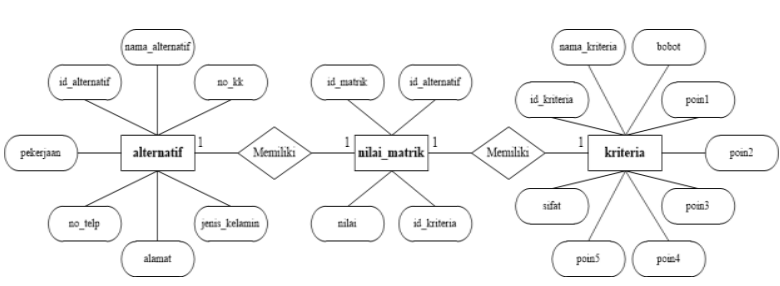

Gambar 11. Entity Relationship Diagram (ERD) Usulan

\section{Logical Record Structure (LRS)}

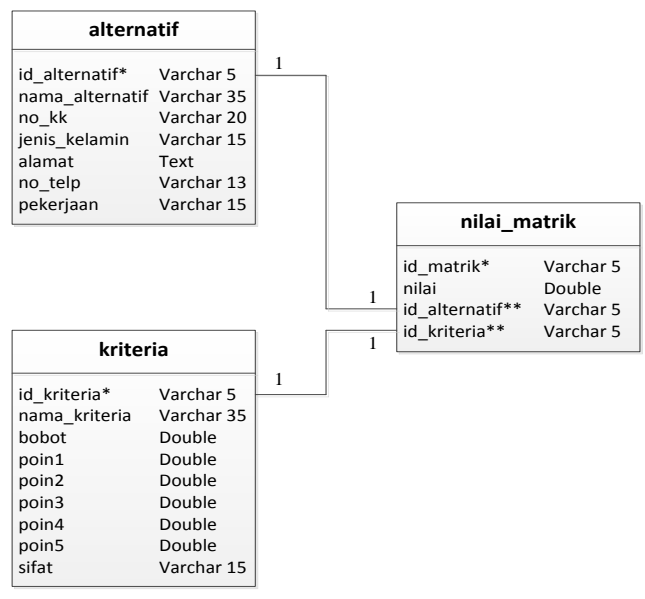

Gambar 12. Logical Record Structure (LRS) Usulan

Pada gambar 12, terdapat 3 tabel, yaitu tabel alternatif, tabel kriteria dan tabelnilai_matrik.

\subsection{Hasil Perhitungan Metode Topsis}

Berikuta dalah hasil perangkingan dari perhitungan metode TOPSIS:

Tabel 8. Hasil Perhitungan Metode Topsis

\begin{tabular}{|l|c|c|}
\hline Alternatif & Nilai RC & Rangking \\
\hline Serah & 0,733 & 1 \\
\hline Andi & 0,689 & 2 \\
\hline Sumirah & 0,530 & 3 \\
\hline Daryo & 0,344 & 4 \\
\hline Ropii & 0,268 & 5 \\
\hline
\end{tabular}

Pada tabeldiatas, dapat diperoleh hasil akhir dari perhitungan menggunakan metode TOPSIS. Dapat di jelaskan bahwa semakin besar RC, maka semakin tinggi rangkingnya, dimana nilai
preferensi/RC dari alternatif yang terbesar merupakan alternative terbaikdan merupakan alternatif yang terpilih, dan alternative dengan nilai optimasi terendah adalah yang terburuk dari data yang ada. Oleh karena itu, alternative Setelah terpilih $\mathrm{s}$ ebagai penerima bantuan RTLH dengan nilai RC tertinggi, yaitu sebesar 0,733 .

\subsection{Implementasi Sistem Penunjang Keputusan Menggunakan Metode TOPSIS Untuk Menentukan Kelayakan Bantuan RTLH Pada Desa Sumbaga \\ Berikut beberapa gambaran antar muka} pengguna proses seleksi penerimaan bantuan RTLH.

1. Halaman Login Admin

Halaman login digunakan untuk menjamin keamanan aplikasi yang tidak bisa diakses oleh semua orang. Untuk login kesistem perlu meng input username dan password dengan benar, kemudian klik tombol login.

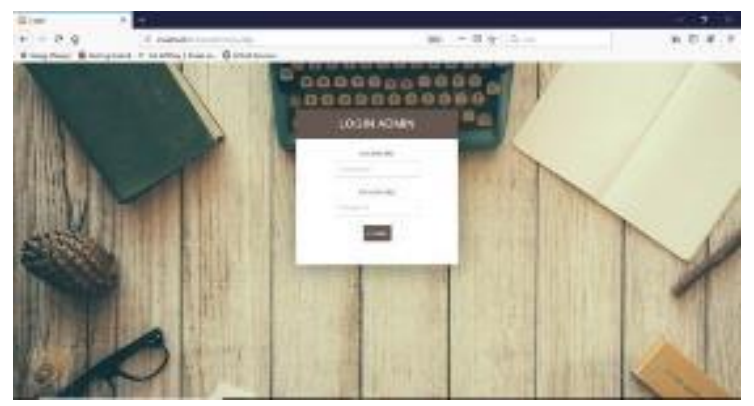

Gambar 13. HalamanLogin Admin

2. HalamanBeranda

Halaman beranda dapat dilihat setelah admin berhasil melakukan login. Terdapat konten selamat datang system penunjang keputusan menggunakan metode TOPSIS untuk menentukan kelayakan bantuanRTLH pada Desa Sumbaga.

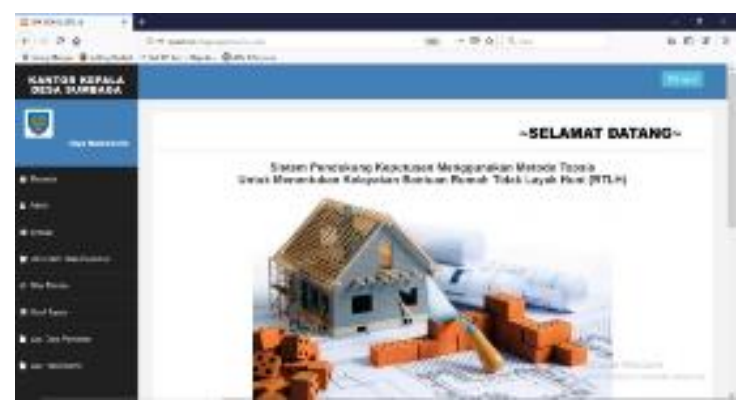

Gambar 14. HalamanBeranda 
3. Halaman Data Alternatif/Data Pemohon Merupakan implementasi dari halaman admin yang dapat menampilkan data alternatif/data pemohon. Data-data alternatif/data pemohon dapat ditambah, diubah maupun dihapus.

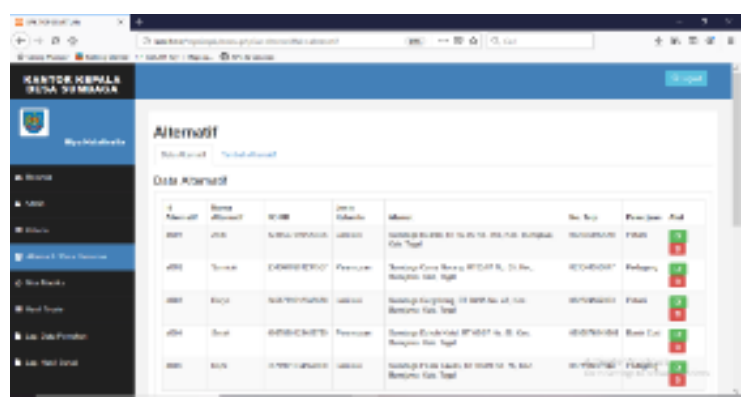

Gambar 17. Halaman Data Alternatif/Data Pemohon

4. Halaman Nilai Matriks

Merupakan implementasi dari halaman admin yang dapat menampilkan form isi nilai matriks.

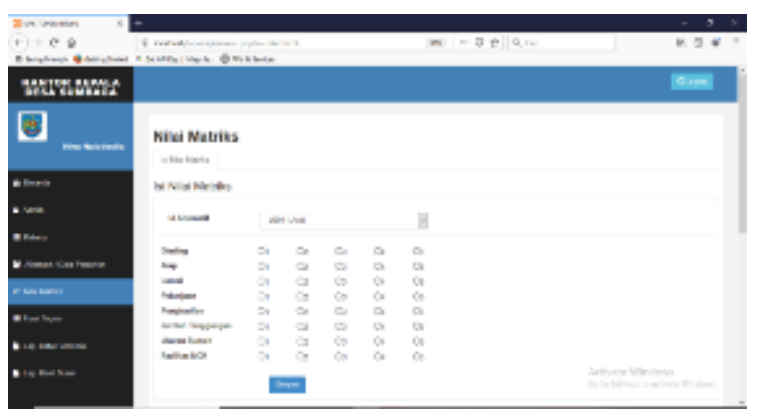

Gambar 18. Halaman Nilai Matriks

5. Halaman Hasil Topsis

Merupakan implementasi dari halaman admin yang dapat menampilkan hasil perhitugan metode TOPSIS. Pada halaman hasil topsis, dapat menampilkan nilai matriks, hasil perhitungan nilai matriks ternormalisasi, nilai bobot ternormalisasi, matriks ideal positif/negatif, jarak solusi ideal positif/negatif, dan nilai preferensi/hasil akhir dari perhitungan.

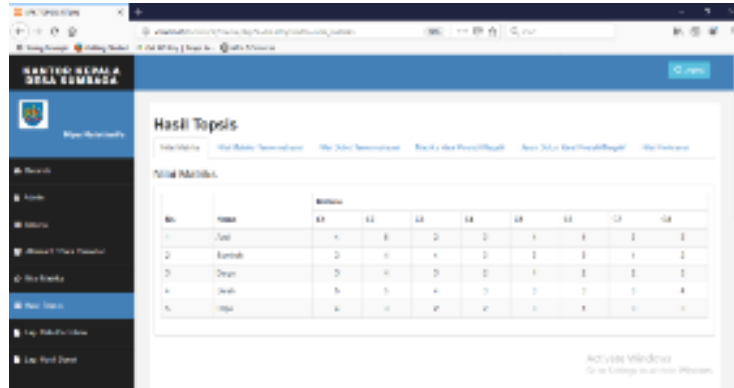

Gambar 19. Halaman Hasil Topsis

6. Halaman Laporan Data Pemohon

Merupakan implementasi dari halaman admin yang dapat menampilkan laporan data pemohon berupa format pdf yang dapat dicetak.

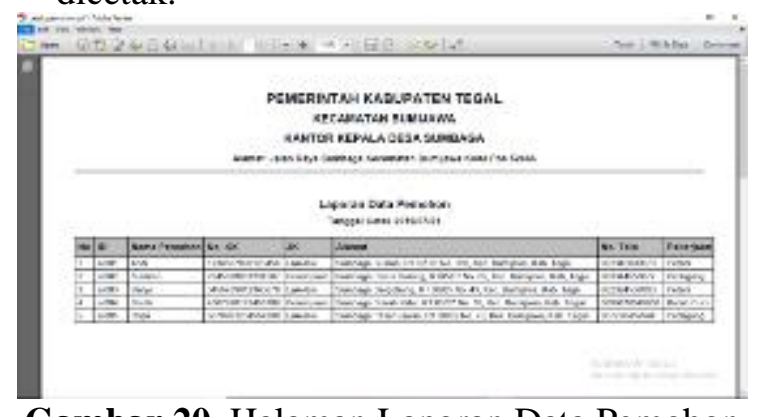

Gambar 20. Halaman Laporan Data Pemohon

\section{SIMPULAN DAN SARAN}

Berdasarkan pembahasan mengenai perancangan system pendukung keputusan menggunakan metode TOPSIS untuk menentukan kelayakan bantuan rumah tidak layak huni (RTLH) pada Desa Sumbaga, penulis dapat menyimpulkan dari pokok bahasan, yaitu tersedianya suatu SPK pada Desa Sumbaga dapat membantu pihak desa dalam menentukan kelayakan bantuan RTLH. SPK akan lebih mempercepat waktu pemilihan calon penerima bantuan RTLH pada Desa Sumbaga dan lebih mempermudah desa dalam pelaksanaan perangkingan/ pengurutan dibandingkan dengan perencanaan pemilihan dengan metode manual sehingga dapat membantu kelancaran proses evaluasi dalam pemilihan penerimaan bantuan RTLH kedepannya.

SPK menggunakan metode TOPSIS untuk menentukan kelayakan bantuan RTLH dapat memberikan kemudahan bagi pihak desa dalam menentukan calon penerimaan bantuan RTLH dan memudahkan pihak desa dalam pengolahan maupun penyimpanan data karena dalam perhitungannya, metode TOPSIS dapat memberikan solusi keputusan berdasarkan hasil rangking kumulatif, dimana nilai preferensi/RC 
dari alternatif yang terbesa rmerupakan alternative terbaik dan alternatif yang terpilih, sedangkan alternative dengan nilai optimasi terendah adalah yang terburuk dari data yang ada, sehingga SP Kmenggunakan metode TOPSIS dapat menghasilkan laporan atau informasi yang cepat dan dapat menghasilkan hasil yang tepatsasaran.

\section{REFERENSI}

[1] Chintya Irwana, Z. F. (2018). Spk: Analisa Metode Moora Pada Warga Penerima Bantuan Renovasi Rumah. Jti, Vol 10 No.1 , 47-54.

[2] Hotmoko Tumanggor, M. H. (2018). Penerapan Metode Vikor Dalam Penentuan Penerima Dana Bantuan. Jurnal Riset Komputer (Jurikom), Vol. 5 No. $1,71-78$.

[3] Irmayani \& Suradi. (2018). Penanggulangan Kemiskinan Berbasis Keterpaduan Data Di. Sosio Konsepsia Vol. 8, No. 01 , 1-13.

[4] Vadreas et al.,. (2018). Sistem Penunjang Keputusan Penentuan (Spk) Bantuan Dana Pembangunan Rumah Tidak Layak Huni (Rtlh) Dengan Metode Multi Factor Evoluation Process (Mfep). Jurnal Teknoif Vol. 6 No. 1 , 18-23.

[5] Fauzi, W. (2016). Sistem Pendukung Keputusan Penerima Bantuan Dana Rutilahu. Seminar Nasional Teknologi Informasi Dan Komunikasi , 432-439.

[6] Mubarok et al. (2019). Sistem Pendukung Keputusan Kelayakan Pemberian Kredit Dengan Metode Topsis. Jurnal Informatika, Vol.6 No.1, 37-46.

[7] Fatkhurrochman \& Astuti. (2018). Analisis Perbandingan Metode Topsis Dan Saw Dalam. Seminar Nasional Teknologi Informasi Dan Multimedia , 6772.

[8] Pramudita \& Rizaldi. (2015). Perbandingan Metode Topsis Dan Saw Dalam Penempatan Karyawan. Semnaskit , 126-130.

[9] Baidawi, P. \&. (2018). Penerapan Metode Topsis Pada Peningkatan Kinerja Karyawan. Jurnal Informatika, Vol.5 No.2 , 287-294.

[10] Irawati, D. (2018). Sistem Pendukung Keputusan Penerimaan Dana Bos Untuk Sekolah Dasar Dengan Metode Ahp
(Dinas Pendidikan Kec. Sei Kepayang). Riau Journal Of Computer Science Vol.4 No.2, 47-56.

[11] Shalahuddin, S. \&. (2018). Perancangan Aplikasi Penjualan Dengan Metode Waterfall. Jurnal Petir Vol. 11 No. 1 , 924.

[12] Augusto, J., \& Guterres, D. (2017). Pemanfaatan Metode Saw Dan Topsis Sebagai Media Pendukung Keputusan Pemberian Bantuan Rumah Layak Huni, 51-56.

[13] Siti Rendani Anjaryanti, Y. R. (2017). Sistem Pendukung Keputusan Kelayakan Pembiayaan Menggunakan Metode Analytical.Jurnal Informatika, 82-93

[14] Jamaludin, I., Sudarsono, N., Mustika, A. I., Informatika, J. T., \& Masalah, L. B. (2014). Sistem Penunjang Keputusan Kelayakan Penerima Bantuan Dana Rutilahu Dengan Metode Ahp, 276-283.

[15] Yulianti, E., Jurusan, D., Informatika, T., Industri, F. T., Jurusan, M., Informatika, T., ... Weighting, S. A. (2018). Sistem Pendukung Keputusan Seleksi Penerima Bedah Rumah Menggunakan Metode Simple Additive Weighting ( Saw ) ( Studi Kasus: Dinas Sosial Dan Tenaga Kerja Kota Padang ), 6(2). Https://Doi.Org/10.21063/Jtif.2018.V6 .2 . 